\title{
Validity and repeatability of three commercially available in-shoe pressure measurement systems
}

\author{
Carina Price, Daniel Parker, Christopher J Nester ${ }^{*}$ \\ From 4th Congress of the International Foot and Ankle Biomechanics (i-FAB) Community \\ Busan, Korea. 8-11 April 2014
}

\section{Background}

In-shoe pressure measurement devices are commonly used in research and clinical settings to quantify pressure on the plantar foot. Various in-shoe pressure measurement devices are currently available and they differ in their size, number of sensors, sensor type and therefore their loading response and accuracy. Previous comparisons focus on pressure plates [1]. An in-shoe study highlighted that the F-Scan system became erroneous at pressures over $200 \mathrm{kPa}$ and the repeatability of the Novel device was high [2]. However the long loading durations (11 minutes) studied has limited application to a real-life setting. The validity and repeatability of each system effects their appropriateness for applications within clinical and research test settings. This abstract, therefore aims to establish the suitability of each device to test protocols with differing loading magnitudes and durations.

\section{Methods}

Three in-shoe pressure measurement devices (Medilogic, Tekscan and Pedar, Figure 1) were examined for their repeatability and validity in a 2 day $\mathrm{x} 3$ repeated trial design. The testing procedure was undertaken in the Novel calibration device (TruBlue) applying an even load over the entire insole surface for UK 4 and 10 insoles. The protocol applied a range of pressures $(50,100,200,300$,

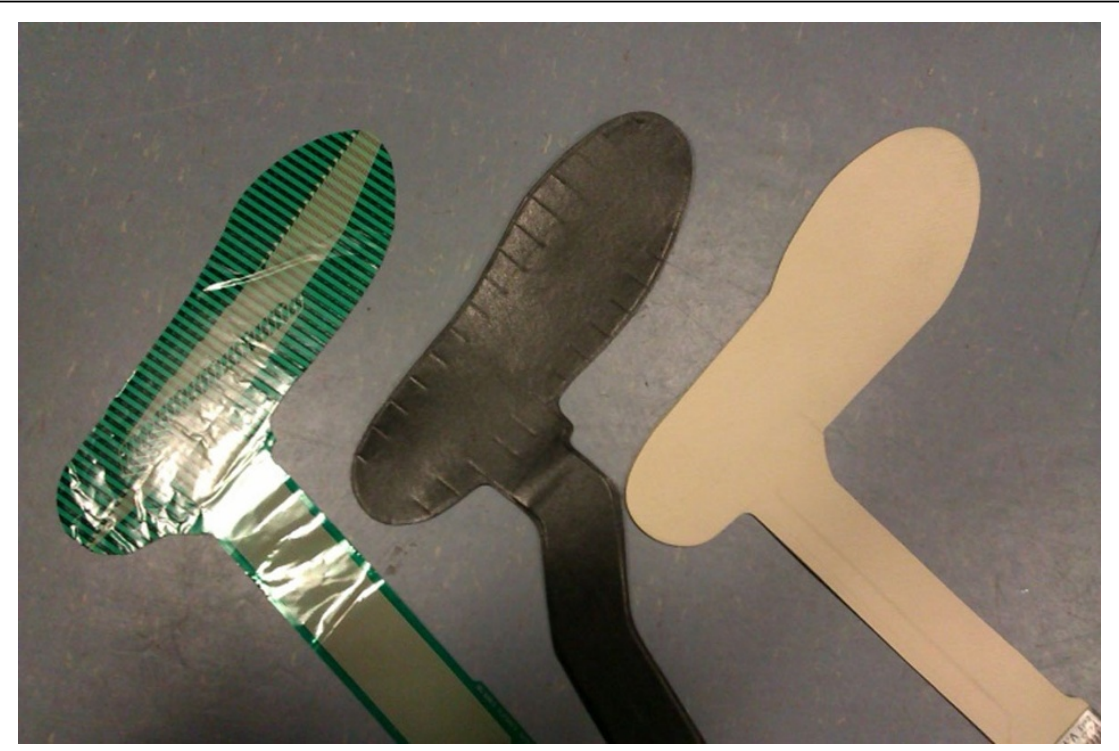

Figure 1 Test insoles in size 4 from left to right: Tekscan, Medilogic, and Pedar. 
400, 500 and $600 \mathrm{kPa}$ ) for $0-30$ seconds. The repeatability (ICC) and validity (RMSE) of the held load (for 0, 2, 10 and 30 seconds) were outcome variables.

\section{Results}

The Pedar system displayed low overall RMSE (3.5 kPa) for all magnitudes and durations applied and a peak value of $7.5 \mathrm{kPa}$ when measured at $600 \mathrm{kPa}$ for 30 seconds. The Tekscan $(31.5 \mathrm{kPa})$ and Medilogic $(27.3 \mathrm{kPa})$ systems RMSE was substantially higher, with maximum RMSE values of 58.4 and 50.4 respectively. The between-day repeatability of the measured pressure values varied between systems. Medilogic ICC values ranged from .334.947 at 100 and $600 \mathrm{kPa}$ respectively with a mean of .667 . Pedar ICC values ranged from .345-.917 kPa at 300 and $600 \mathrm{kPa}$ respectively with a mean of .638 . Tekscan ICC values ranged from .042-.919 at 50 and $500 \mathrm{kPa}$ respectively with a mean of .614, after exclusion of the $600 \mathrm{kPa}$ data. All insole systems produced the highest ICC values for pressure values above $100 \mathrm{kPa}$.

\section{Conclusions}

The choice of an appropriate pressure measurement device must be based on the, duration of loading, magnitude of loading and the outcome variables sought. Medilogic and Tekscan are most effective between 200-300 kPa; Pedar performed well across all pressures.

Published: 8 April 2014

\section{References}

1. Giacomozzi C: Appropriateness of plantar pressure measurement devices: A comparative technical assessment. Gait \& Posture 2010, 32:141-144.

2. McPoil TG, Cornwall MW, Yamada W: A comparison of two in-shoe plantar pressure measurement systems. Lower Extremity 1995, 2:95-103.

doi:10.1186/1757-1146-7-S1-A67

Cite this article as: Price et al: Validity and repeatability of three

commercially available in-shoe pressure measurement systems. Journal

of Foot and Ankle Research 2014 7(Suppl 1):A67.

\section{Submit your next manuscript to BioMed Central} and take full advantage of:

- Convenient online submission

- Thorough peer review

- No space constraints or color figure charges

- Immediate publication on acceptance

- Inclusion in PubMed, CAS, Scopus and Google Scholar

- Research which is freely available for redistribution

Submit your manuscript at www.biomedcentral.com/submit 